\title{
Biotite (Black Mica) as an Adsorbent of Pesticides in Aqueous Solution
}

\author{
Leonardo Paulino Werneck Ceolin (D) Terencio Rebello Aguiar Junior • \\ Maria Manuela Morais • Joana Rosado • Ana Denise Veloso • \\ Berenice Ferreira Paulino • Lucas Luscher Martins
}

Received: 6 March 2015 / Accepted: 4 June 2015 /Published online: 2 July 2015

(C) Springer International Publishing Switzerland 2015

\begin{abstract}
Chemical contamination of water resources on the planet generates a range of environmental disturbances which impair ecosystems. Humans ingest such chemicals often present in water. Conventional treatments fail to remove these contaminants from water, requiring complementary methods such as activated carbon filters, reverse osmosis, or distillation, which are expensive and seldom used in the public water supply. In recent years, there has been a search for
\end{abstract}

L. P. W. Ceolin $(\bowtie)$

University of Lisbon, School of Agronomy, Tapada da Ajuda, 1349-017 Lisbon, Portugal

e-mail: leoceolin@yahoo.com.br

T. R. Aguiar Junior

Federal University of Paraná, Hydrogeological Research Laboratory, Centro Politécnico, 81990-551 Curitiba, Paraná, Brazil

M. M. Morais $\cdot$ J. Rosado

Instituto Ciências da Terra (ICT), Pólo da Universidade de

Évora, Rua Romão Ramalho n. 59, 7000-671 Évora, Portugal

A. D. Veloso

Ana Denise Veloso, Fundação D. Cabral, Rua Bernardo

Guimarães, 3071 Sto. Agostinho, 30140-083 Belo Horizonte,

MG, Brazil

\section{B. F. Paulino}

Berenice Ferreira Paulino, UFMG, Avenida Presidente Antônio Carlos 6627, Pampulha, Belo Horizonte, MG 31270-901, Brazil

\section{L. Martins}

Lucas Luscher Martins, FACUL-UL, Dept. de Ecologia. Faculdade de Ciências da Universidade de Lisboa, Campo Grande, 1749-016 Lisbon, Portugal alternative eco-friendly, low-cost methods which can effectively remove these contaminants. This study was conducted to test the effectiveness of biotite (black mica), an igneous mineral of the mica group, in removing pesticides from water. A trial was designed to assess the rate of pesticide removal using a methodology based on axes of variation of $\mathrm{pH}$, temperature, concentration, and time. The pesticides tested were atrazine, fluazifopp-butyl, lambda-cyhalothrin, chlorpyrifos, and lactofen. The results showed higher removal rates in acidic conditions ( $\mathrm{pH} 3$ ) and temperatures between 20 and $30{ }^{\circ} \mathrm{C}$, requiring about $6 \mathrm{~h}$ to reach maximum adsorption. More than $80 \%$ of all the pesticides were adsorbed. The best result was obtained for fluazifop (94.2\%) in $6 \mathrm{~h}$, under $\mathrm{pH} 3$, and temperature of $25^{\circ} \mathrm{C}$. The study revealed that biotite has a high absorption capacity of complex and varied compounds. These findings signal the need for further studies and tests. Due to the high cost of pesticide analysis, which can only be made using a chromatograph mass spectrometer, financial resources will be required.

Keywords Pesticides · Removal · Adsorption · Biotite Contaminants · Water quality

\section{Introduction}

The word "pesticide" is an umbrella term encompassing all the chemicals that are used to eliminate or control pests in agriculture, such as herbicides (weeds), insecticides (insects), fungicides (fungi), nematocides 
(nematodes), and rodenticides (vertebrate poisons). After the second World War, pesticides were developed and began to be widely used to control a variety of pests that hindered agricultural production (Sanches et al 2003).

Agro-pesticides can be divided into inorganic compounds, synthetic organic chemicals, and biopesticides. Inorganic compounds are some of the earliest chemicals used for pest control such as sulfur, lead arsenate, copper and lime mixtures, borax and chlorates, and mercury compounds. Inorganic pesticides contain chemical elements that do not break down, and most can cause severe environmental and toxicological damage. Some like lead, arsenic, and mercury are very toxic and often accumulate in the soil.

Synthetic chemicals are relatively new. Their discovery stemmed from research into nerve gas weapons in World War II, when scientists realized that the compounds also killed insects. DDT proliferated in the 1930s and 1940s reducing malaria and improving crop yields. However, they proved to be extremely harmful not only to insects but to the whole ecosystem (Gold et al. 2001). Thus, although pesticides were a key contributor to the Green Revolution, they now threaten the long-term survival of major ecosystems by disrupting predator-prey relationships and the whole balance of biodiversity (Sanches et al. 2003; Rissato et al. 2004; Regitano and Bonfleur 2011).

Unsafe handling of pesticides is harmful to the environment for poisonous substances can contaminate areas quite far from where they were used. Consequently, their inadequate and excessive use is often reported. Appelgren (FAO, 1994b) points out that economic factors contribute to the amount of pesticide pollution in some countries, and that water pollution by pesticides is often caused by inadequate storage and distribution of agrochemicals. In the USA, the USEPA's National Pesticide Survey found that $10.4 \%$ of community wells and $4.2 \%$ of rural wells contained detectible levels of one or more pesticides (US-EPA 1992). In a study of groundwater wells in agricultural southwestern Ontario-Canada, $35 \%$ of the wells tested positive for pesticides on at least one occasion (Lampman 1995). Once in the soil, pesticides can be transported in large quantities by rainwater, affecting mainly surface water such as rivers and lakes. Pesticides can also leach into groundwater and be found in wells used to supply water for domestic use or for watering livestock. The relative importance of these two forms of transport depends largely on soil type and topography of the region (Rigitano and Barbosa 1994; Moreira and Cruz 1996). Additionally, pesticides could have deleterious effects on human health through skin contact in unsafe handling, inhalation by breathing of dust or spray, or by ingestion of contaminated food or water. The effects range from skin lesions to cancers, tumors, immune system suppression, DNA damage, reproductive impairment, physical deformities, to death of the organism (Hashmi et al. 2011; Damalas and Eleftherohorinos 2011).

Andreoli (1993) and Aguiar et al. (2014, 2015 ) reports that by 1970 , Brazil had become the world's third largest user of pesticides, only exceeded by France and the USA, but less than $15 \%$ of the active ingredients marketed in Brazil were analyzed. From 1976 to 1984 , a study of 17 substances, among them 11 organochlorine pesticides in the Paraná River basin, found that $91.4 \%$ of ambient samples contained at least one. In the Pirapó subbasin, $97.2 \%$ of ambient water supply samples and all the samples from springs contained pesticide residues. Andreoli (1993) also reported that, in 1985, most cases of intoxication were caused by organophosphate pesticides.

Older pesticides and other hydrophobic carcinogens such as PAHs and PCBs may be found in water samples. The range of concentration of suspended solids in rivers is often between 100 and $1000 \mathrm{mg} / \mathrm{l}$ except during major runoff events when concentrations can greatly exceed these values. Pristine tropical rivers have very low suspended sediment concentrations, but increasingly, these are a rarity due to agricultural expansion and deforestation in tropical countries (Appelgren 1994).

A number of techniques are used in water treatment so as to reduce potentially harmful contaminants. Among the most common methods are activated carbon, reactions with oxidants such as potassium ferrate and chlorine, and free radical degradation using ozonation and UV exposure. There have been numerous research papers showing the presence of pesticides in consumed food, even in the water supply of human settlements, most of which could not be removed just by using conventional techniques such as activated granular charcoal filters (CAG) or clay. A study to evaluate the efficiency of ozonation, chlorination, activated carbon, UV radiation, and ferrate for removing atrazine, glyphosate, and alachlor from water, three of the most commonly used pesticides linked to detrimental health effects was conducted at the Worcester Polytechnic Institute (Bourgeois et al. 2012). The results 
demonstrated that activated carbon and UV with hydrogen peroxide were most successful at reducing pesticide concentrations after $24 \mathrm{~h}$ but UV without hydrogen peroxide led to significant by-product formation and persistence for alachlor and glyphosate, but removed $87 \%$ of atrazine in $75 \mathrm{~min}$ and that peroxide led to byproduct formation as well but with continued contact. Hypochlorite ion removed a maximum of $59 \%$ of alachlor and $11 \%$ of atrazine at $\mathrm{pH} 9$. The results obtained with ozonation showed significant by-product formation for alachlor, tested for $90 \mathrm{~min}$, but removed $17 \%$ of atrazine in $30 \mathrm{~min}$ (Bourgeois et al. 2012). These findings reinforce the need for additional effective, low cost, and feasible methods (Libânio et al. 2005; Rissato et al. 2004). Adsorption experiments in search of a solution were conducted by Elsabawy et al. (2012) and Chakraborty et al. (2007), and their results showed evidence that biotite adsorbed heavy metals and arsenic in aqueous solution, respectively.

Adsorption comprises a broad spectrum of physical, biological, and chemical operations, and the forces that account for it are named adsorption forces. The change in concentration of a given substance at the interface as compared with the neighboring phases is referred to as adsorption. Depending on the type of phases in contact, we can consider this process in the following systems: liquid-gas, liquid-liquid, solid-liquid, and solid-gas (Dabrowski 2001). Adsorption can result either from the universal van der Waals interactions - physical adsorption, physisorption, or it can have the character of a chemical process - chemical adsorption or chemisorption. Contrary to physisorption, chemisorption occurs only as a monolayer. Physical adsorption can be compared to the condensation process of the adsorptive. As a rule, it is a reversible process that occurs at a temperature lower or close to the critical temperature of an adsorbed substance (Dabrowski 2001). Studies on adsorption processes both from diluted solutions and from solutions in the full range of their concentrations are of great importance in the industrial separation of liquid mixtures as well as in environmental protection techniques. Moreover, adsorption from multicomponent solutions is a basis for the theory of adsorption liquid chromatography (Dabrowski 2001). Practical application of adsorption processes is based mainly on selective uptake of individual components from their mixtures by other substances. Selective adsorption was discovered by Tswett in 1903 (Dabrowski 2001). He took advantage of this phenomenon to separate chlorophyll and other plant pigments by means of silica materials. This separation was possible due to different adsorption affinity of silica gel with regard to various pigments. The technique proposed by Tswett has been called as 'column solid-liquid adsorption chromatography'. This discovery was not only the beginning of a new analytical technique but also the origin of a new field of surface science (Dabrowski 2001).

Biotite is a common phyllosilicate mineral within the mica group, with the approximate chemical formula $\mathrm{K}(\mathrm{Mg}, \mathrm{Fe})_{3} \mathrm{AlSi}_{3} \mathrm{O}_{10}(\mathrm{OH}, \mathrm{F})_{2}$ found in a wide variety of igneous and metamorphic rocks. It is a silicate consisting of flexible sheets, or lamellae, which easily flake off, and Mohs hardness of 2.5-3.0. It contains iron, magnesium, aluminum, silicon, and hydrogen, forming sheets that are weakly bound together by potassium ions. It is sometimes called "iron mica" because it is more iron-rich than phlogopite. Its weight depends on the amount of iron it contains. The chemical elements present produce different kinds of biotite. The weathering of biotite breaks it up into clay, the finest soil granulometry, whose capacity to remove and filter particles and contaminants is well known (Howie and Zussman 1963; Dana 1981; Anthony et al. 2003).

The adsorption test was carried in a laboratory experiment, and in this context, the study reported here aimed at assessing if biotite, used as a mineral adsorbent, was capable of removing atrazine, fluazifop-pbutyl, lambda-cyhalothrin, chlorpyrifos, and lactofen, some of the most commonly used pesticides in soy and corn crops, from contaminated water.

\section{Methodology}

\subsection{Setting Experiment Conditions}

For the trials, $10 \mu \mathrm{g} / \mathrm{l}$ standard solutions of atrazine, fluazifop-p-butyl, lambda-cyhalothrin, chlorpyrifos, and Lactofen were added to 126 shakers containing 11 of water previously purified in a Milli-Q system (Millipore, Bedford, MA). The water $\mathrm{pH}$ was set to 3, 7 , and 9 to test whether there would be differences in the results. Then, $10 \mathrm{~g}$ of biotite was added to the shakers, having been previously ground, passed through a 60mesh sieve, and automatically quartered, according to the ASTM norms. The shakers were covered with aluminum foil to prevent photodegradation of the pesticides and were then placed in a shaking table, keeping 
pressure and temperature under control for 30, 60, 120, $240,360,720$, and $1440 \mathrm{~min}$. The samples were immediately analyzed at the end of each period of time. The results showed optimal adsorption at $\mathrm{pH} 3$ and $360 \mathrm{~min}$.

Since it was observed that $\mathrm{pH} 3$ and a period of 360 min promoted higher removal rates, they were maintained in this second trial. The same sample preparation process mentioned above was repeated in 24 shakers heated at $10,20,30$, and $40^{\circ} \mathrm{C}$ by a shaker incubator (margin of error $\pm 0.5^{\circ} \mathrm{C}$ ). Optimal results were obtained at $30{ }^{\circ} \mathrm{C}$.

In the maximum adsorption capacity trials, solutions of concentrations $5,20,40$, and $50 \mu \mathrm{g} / \mathrm{l}$ of the pesticides were added to 24 shakers and placed in an incubator shaker table at $30^{\circ} \mathrm{C}, \mathrm{pH} 3$ for a period of $360 \mathrm{~min}$.

A sample of biotite was obtained from a company based in Sao Paulo, Brazil, called LP Minerals, at the price of approximately $\$ 15$ per kilogram. Black mica is a common, cheap mineral found not only in the states of Bahia and Minas Gerais, Brazil, but also in many countries all over the world.

\subsection{Extracting Pesticides from Water Samples}

Standard atrazine, fluazifop-p-butyl, lactofen, lambdacyhalothrin, and chlorpyrifos with a degree of purity of $99 \%$ were obtained from Sigma-Aldrich (Missouri, USA). The solutions $(10 \mathrm{mg} / \mathrm{ml})$ and the dilutions $(0.001,0.01,0.1,1$ to $10,20,40$, and $50 \mu \mathrm{l})$ were prepared in ethyl acetate to perform the calibration curve. The standards and the solutions were kept at -4 C. The solvents - ethyl acetate, methanol and waterwere Merck chromatography level (Darmstadt, Germany). Atrazine-D5 with a degree of purity of $99 \%$, from Supelco (Bellefonte, PA EUA), was used as a surrogate standard.

The extraction protocol used, optimized by Aguiar et al. (2015), was in accordance with SANCO/ 10232/2006 UE (European Commission, 2006b). Before the extraction, $0.1 \mu \mathrm{l}$ of atrazine-D5 (99\% purity, Bellefonte, PA, USA) was added to the 1-1 sample as a surrogate standard. The samples were initially filtered using a $0.45 \mu \mathrm{m}$-pore-size cellulose membrane with a diameter of $47 \mathrm{~mm}$ (Merck Millipore-Darmstadt, Germany). One liter of water sample was extracted using solid phase extraction C18 cartridges (SPE Milford, MA, USA). The cartridges were first cleaned with $6 \mathrm{ml}$ of ethyl acetate, $6 \mathrm{ml}$ of methanol, and $6 \mathrm{ml}$ of purified water (Milli-Q, Millipore, Bedford, MA), and the samples were then percolated using a vacuum system (JTBaker-Phillipsburg, NJ) at a flow rate of $6 \mathrm{ml} /$ min. After that, the cartridges were dried under vacuum for $15 \mathrm{~min}$ to remove excess water and then extraction was performed with $6 \mathrm{ml}$ of ethyl acetate and $6 \mathrm{ml}$ of methanol. The extract was dried with a gentle flux of ultrapure argon White Martins (Praxair Technology Inc., USA) using a dry block $\left(40^{\circ} \mathrm{C}\right.$, Marconi, SP, BRA) and reconstituted in $100 \mu \mathrm{l}$ of ethyl acetate. The samples $(1 \mu \mathrm{l})$ were transferred to vials and placed in a gas chromatography coupled to a mass spectrometer (GC-MS).

GC-MS analysis was performed using a Varian 431GC gas chromatograph coupled to a Varian 20 MS mass spectrometer equipped with a VF 5 ms capillary column (30 $\mathrm{m} \times 0.25 \mathrm{~mm}, 25-\mu \mathrm{m}$ film thickness. The GC oven was programmed from $90{ }^{\circ} \mathrm{C}$ (hold $0.5 \mathrm{~min}$ ) to $160^{\circ} \mathrm{C}$ (hold $4 \mathrm{~min}$ ) at $15{ }^{\circ} \mathrm{C} \mathrm{min}^{-1}$ then to $280{ }^{\circ} \mathrm{C}$ (hold $10 \mathrm{~min}$ ) at $20^{\circ} \mathrm{C} \mathrm{min}^{-1}$. The GC interface and ion source were 280 and $200{ }^{\circ} \mathrm{C}$, respectively. The ion trap mass spectrometer was operated in electron impact ionization with ionization energy of $70 \mathrm{eV}$ and emission current of $300 \mathrm{~mA}$. Helium at a constant flow of $10 \mathrm{ml} \mathrm{min}^{-1}$ was used as carrier gas. The injection volume was $1 \mu \mathrm{l}$ in a splitless mode $(1 \mathrm{~min})$ with injector temperature at $250{ }^{\circ} \mathrm{C}$. From the collision-induced dissociation (MS/ MS) three mass fragment ions were selected for each compound, atrazine ( $\mathrm{m} / \mathrm{z} 122^{*}, 132$, and 215$)$, chlorpyrifos $\left(\mathrm{m} / \mathrm{z} 258^{*}, 286\right.$, and 314), fluazifop-p-butyl $(\mathrm{m} / \mathrm{z}$ 254, 238*, and 282), lambda-cyhalothrin ( $\mathrm{m} / \mathrm{z} 152^{*}$, 154 , and 181) and lactofen ( $\mathrm{m} / \mathrm{z} 223^{*}, 300$, and 344), and the major mass fragment ions were used as precursor ion. The marked mass fragment ions were used for quantification analysis and the other two for structural confirmation. The stock solutions were prepared for all agrochemicals (99\% purity, Sigma-Aldrich, Missouri, USA) at $10 \mathrm{mg} \mathrm{ml}^{-1}$ in ethyl acetate and were kept in $-4{ }^{\circ} \mathrm{C}$. Atrazine-D5 was checked using the following ions $m / z$ 127, 139, 222. A calibration curve with diluted standards was performed in 0.01-30 $\mu \mathrm{g} 1^{-1}$. Calibration curves resulted in correlation coefficients of 0.99 and relative standard deviation below $9 \%$ (n 4) for all the compounds. The lowest quantification point was $0.01 \mu \mathrm{g} \mathrm{l}^{-1 \mathrm{~d}}$, in which all compounds had significant signs. Recovery studies were performed with a mixture of five agrochemicals in free-agrochemicalsgroundwater at a concentration of $1 \mu \mathrm{g} 1^{-1}$, and recovery values ranged from 83 to $97 \%$ with a standard deviation below $12 \%$ (n 5 ) for all analyses. 
The protocol used was also in agreement with the SANCO/10232/2006EU (European Commission, 2006). The identification and confirmation of target compounds were made according to the following criteria: (I) retention time deviation from a standard of less than $2 \mathrm{~s}$, (II) three characteristic $m / z$, (III) intensities of the characteristic $\mathrm{m} / \mathrm{z}$ compared to standard $\mathrm{m} / \mathrm{z}$ not over $15 \%$ variation.

\subsection{Data Analyses}

Statistics were calculated for each experiment duration (30, 60, 120, 240, 360, 720, and $1440 \mathrm{~min}), \mathrm{pH}(3,7$, and 9), temperature $\left(10,20,25,20\right.$, and $\left.40{ }^{\circ} \mathrm{C}\right)$, and pesticide concentration $(5,10,20,40$, and $50 \mu / 1)$. Differences between $\mathrm{pH}$ and experiment duration were tested with the nonparametric Kruskal-Wallis test, as data failed to meet the assumptions of normal distribution. Post hoc pairwise comparisons were computed to identify in each group (i.e., different $\mathrm{pH}$ and experiment duration) differences that occur. All statistical analyses were performed in IBM SPSS Statistics 19.

\section{Results}

\subsection{Effect of $\mathrm{pH}$ and Time Variation}

The adsorption trial was designed to assess the effect of three different $\mathrm{pH}$ conditions (3, 7, and 9) on pesticide removal rates. The graphs below show the results of each $\mathrm{pH}$ analysis keeping temperature and concentrations unchanged (Fig. 1). Adsorption percentages are shown for $30,60,120,240,360,720$, and $1440 \mathrm{~min}$, respectively.

Results of the Kruskal-Wallis tests showed that all relative adsorption rates of pesticides were significantly different under different $\mathrm{pH}$ conditions (atrazine, $H(2)=$ 22.366, $p=0.000, n=63$; chlorpyrifos, $H(2)=20.414$, $p=0.000, n=63$; fluazifop, $H(2)=41.898, p=0.000, n=$ 63; lambda, $H(2)=30.318, p=0.000, n=63$; lactofen, $H(2)=32.895, p=0.000, n=63)$, and the seven preset time spans (atrazine, $H(6)=33.471$, $p=0.000, n=63$; chlorpyrifos, $H(6)=36.798, p=$ $0.000, n=63$; fluazifop, $H(6)=18.148, p=0.006$, $n=63$; lambda, $H(6)=26.324, p=0.000, n=63$; lactofen, $H(6)=26.023, p=0.000, n=63)$.

Post hoc pairwise comparisons showed that all pesticide adsorption rates were significantly higher at $\mathrm{pH} 3$ compared to $\mathrm{pH} 9$ (atrazine, $t=26.643, p=0.000$; chlorpyrifos, $t=25.381, p=0.000$; fluazifop, $t=36.310, p=$ 0.000 ; lambda, $t=28.381, p=0.000$; lactofen, $t=$ $32.286, p=0.000)$. Apart from lambda pesticide, pesticide adsorption rates were also significantly higher at $\mathrm{pH} 3$ compared to $\mathrm{pH} 7$ (atrazine, $t=14.857, p=0.026$; chlorpyrifos, $t=14.976, p=0.024$; fluazifop, $t=21.833$, $p=0.000$; lactofen, $t=18.500, p=0.003$ ).

The results also demonstrate that the length of time affects pesticide concentrations. Optimal values were obtained in $360 \mathrm{~min}$, after which the adsorption rate decreased significantly and actually began to increase: some pesticides showed higher concentrations after 1440 min than in just $360 \mathrm{~min}$.

Additional post hoc pairwise comparisons also showed that the best adsorption rate of all pesticides was obtained in then time span of $360 \mathrm{~min}$ (atrazine, $t=-41.056, p=0.000$; chlorpyrifos, $t=-38.889, p=$ 0.000 ; fluazifop, $t=-26.222, p=0.050$; lambda, $t=$ $-33.778, p=0.002$; lactofen, $t=-34.667, p=0.001$ ).

It was observed that regardless of the period of time, removal rates were always higher in acidic conditions (pH 3, Fig. 1). Overall, variance analysis showed that relative adsorption rates of pesticides were significantly influenced by the experiment duration and $\mathrm{pH}$ conditions.

\subsection{Effect of Temperature and Initial Pesticide Concentration}

\section{a) Testing temperature variation}

Temperatures of 25 and $30{ }^{\circ} \mathrm{C}$ revealed to be the best to achieve higher relative adsorption rates of atrazine, chlorpyrifos, fluazitop-p-butyl, lambda-cyhalothrin, and lactofen. In contrast, temperature limits of 10 and $40{ }^{\circ} \mathrm{C}$ showed a wide variation in pesticide adsorption rates (Fig. 2). Kruskal-Wallis tests showed that all adsorption rates were significantly different between the temperatures $25 / 30{ }^{\circ} \mathrm{C}$, compared to $10 / 20 /$ $40{ }^{\circ} \mathrm{C}$ (atrazine, $H(1)=10.862, p=0.001$; chlorpyrifos, $H(1)=10.883, p=0.001$; fluazifop, $H(1)=9.087$, $p=0.003$; lambda, $H(1)=7.882, p=0.005$; lactofen, $H(1)=5.219, p=0.022)$.

\section{b) Testing pesticides initial concentration}

At $30{ }^{\circ} \mathrm{C}$ temperature, pesticide adsorption rate varies according to pollutant initial concentration (Fig. 3). The 

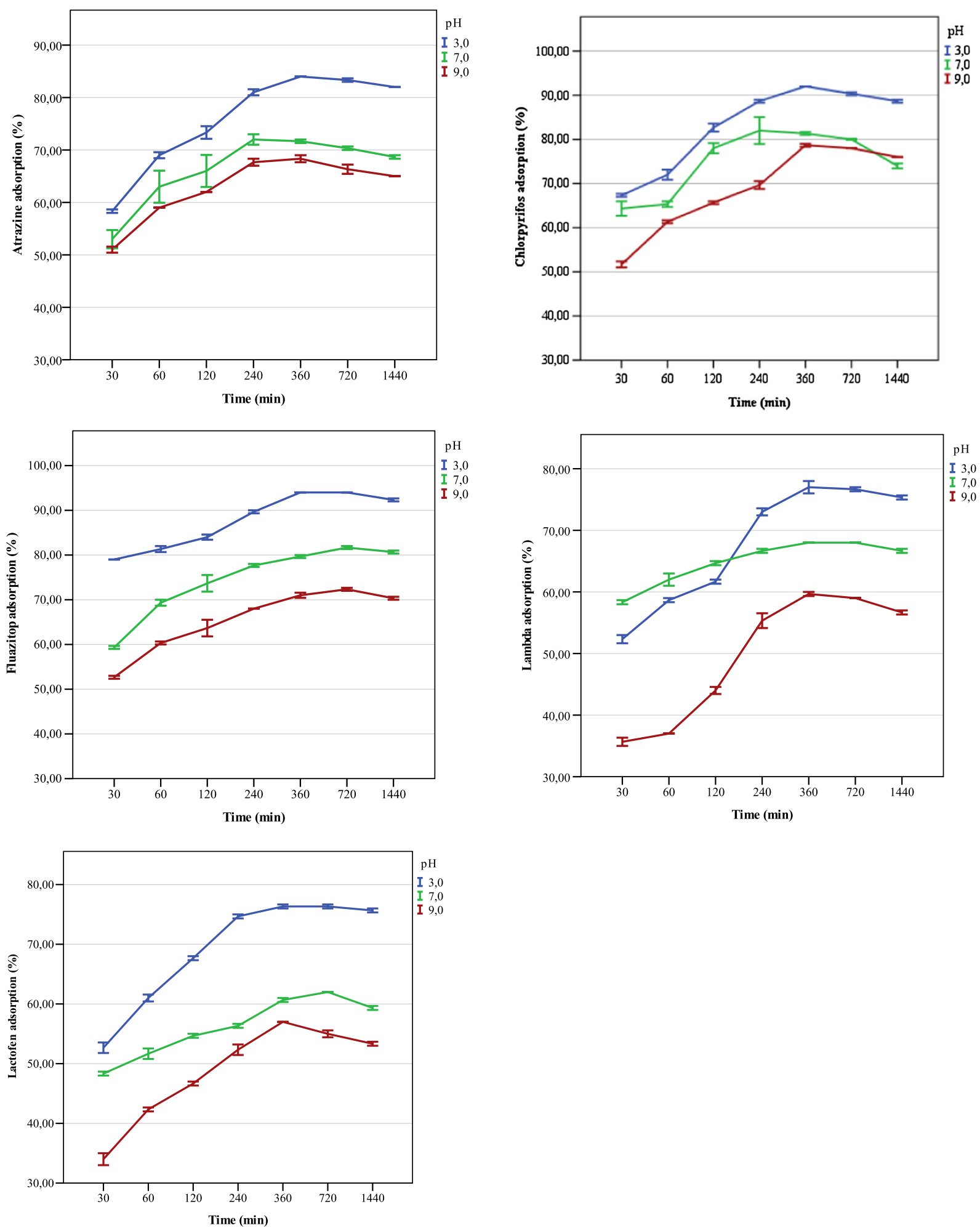

Fig. 1 Relative absorption rates (mean \pm SE; mg/l; three replicates per treatment) of atrazine, chlorpyrifos, fluazitop-p-butyl, lambdacyhalothrin, and lactofen at $\mathrm{pH} 3,7$, and 9 , after 30 to $1440 \mathrm{~min}$ of exposure, at $25^{\circ} \mathrm{C}$ temperature 
Fig. 2 Pesticide absorption rates (mean $\pm \mathrm{SE} ; \mathrm{mg} / \mathrm{l}$; three replicates per treatment) at $\mathrm{pH} 3$, after 360 min of experiment at different temperatures $(10,20,25,30$, and $\left.40{ }^{\circ} \mathrm{C}\right)$

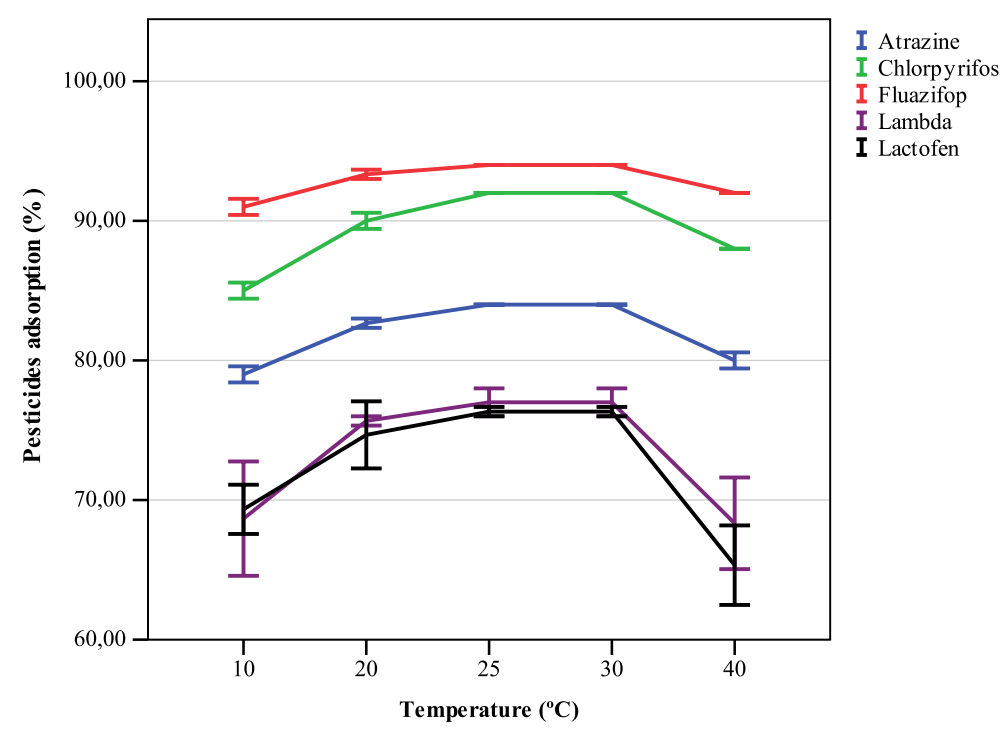

results of the tests of different concentrations ( 5 to $50 \mu \mathrm{l}$ ) showed that the adsorption capability of biotite was maintained and even increased for some pesticides. Kruskal-Wallis tests showed that all pesticide adsorption rates were significantly different between the initial concentrations of $5 / 10 \mu \mathrm{g} / 1$, compared to $20 / 40 / 50$ (atrazine, $H(1)=6.375, p=0.012, n=15$; chlorpyrifos, $H(1)=5.833, p=0.016, n=15$; fluazifop, $H(1)=6.236$, $p=0.013, n=15$; lambda, $H(1)=10.235, p=0.001, n=$ 15 ; lactofen, $H(1)=10.328, p=0.001, n=15)$.

\section{Discussion}

As already mentioned, biotite is a common iron-rich rock-forming mineral, being present in at least some percentage in most igneous and both regional and contact metamorphic rocks. Like other micas, it has a layered structure of iron magnesium aluminum silicate sheets weakly bonded together by layers of potassium ions. These potassium ion layers produce the perfect cleavage (Mannini 2009).
Fig. 3 Pesticide absorption rates (mean \pm SE; three replicates per treatment) at different initial concentrations $(5,10,20,40$, and $50 \mu \mathrm{l})$, at $30^{\circ} \mathrm{C}$ temperature

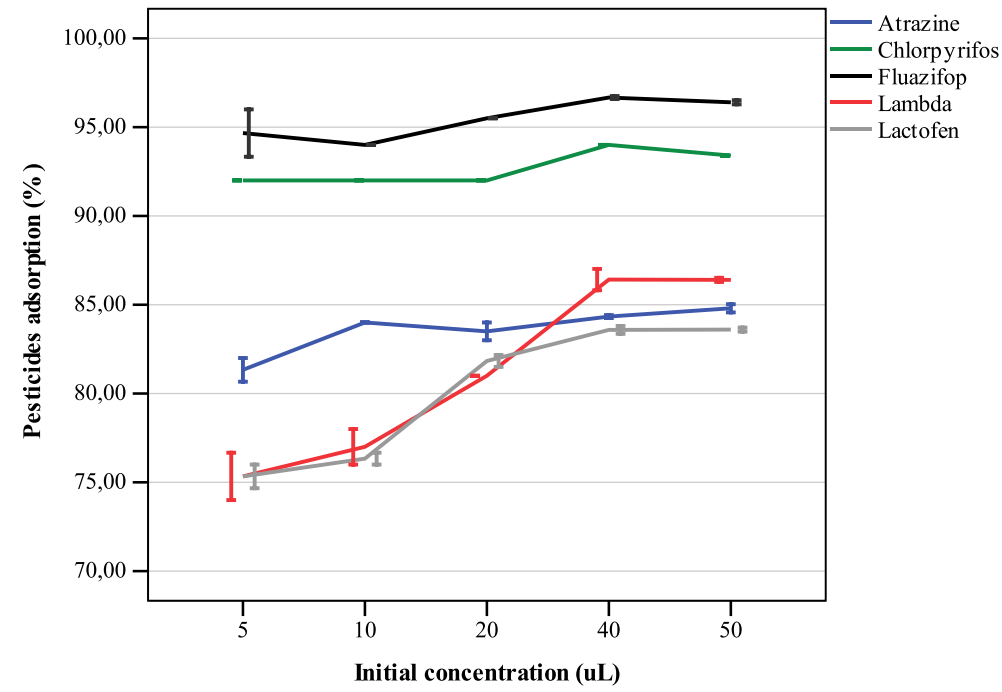


According to Chakraborty (2007), phyllosilicates have three different surface hydroxide groups associated with ruptured bonds along the crystal edge: aluminol, silanol, and Lewis acid groups. Research has demonstrated that the edge sites of micaceous minerals are more reactive than basal surfaces for adsorption. As(V)-Fe(II) reaction products in the presence of phlogopite, a Fe-free mica, is located predominantly on the layer edges. A study on the sorption of $\mathrm{Cu}(\mathrm{II}), \mathrm{Cd}(\mathrm{II})$, and $\mathrm{Pb}$ (II) onto muscovite and biotite in mildly acidic solution revealed that biotite provides greater reactive surface than muscovite.

Biotite's affinity for metal uptake is attributed to different mechanisms of ion exchange and adsorption processes. During the ion-exchange process, metal ions move through the pores of the biotite and channels of the lattice, replacing exchangeable cations (mainly sodium) and additionally exchanging with protons of surface hydroxyl groups. In the case of exchange with sodium, sodium ions placed on the biotite surface exchange with the metal ions in the solution. When the exchange site is a hydroxyl group, exchange reactions occur in which metal ions exchange with the $\mathrm{H}+$ ions. Diffusion is faster through the pores and retarded when the ions move through the smaller-diameter channels. The ion-exchange processes in biotite are affected by several factors such as concentration and nature of cations, $\mathrm{pH}$, and crystal structure of the biotite (Elsabawy et al. 2012).

Our results showed optimal adsorption rates in acidic medium ( $\mathrm{pH} 3$ ), temperature between 20 and $30{ }^{\circ} \mathrm{C}$, and approximately $6 \mathrm{~h}$ for maximum adsorption. After $12 \mathrm{~h}$, the concentration of some pesticides actually increased when compared to the results obtained in $6 \mathrm{~h}$. The adsorption rate was above $80 \%$ for all the pesticides, with fluazifop showing the highest percentage $94.2 \%$ (Fig. 1).

The study revealed the high effectiveness of biotite in adsorbing complex compounds such as the five pesticides analyzed. It suggests the feasibility of an innovative low-cost and efficient method for adsorbing pesticides. The results indicated that only in $30 \mathrm{~min}$, it was possible to remove between 52 and $79 \%$ of the five pesticides studied (Fig. 2). If one compares the efficacy, simplicity, and low cost of biotite with the complex, pricey, and often disappointing results (by-product formation, among others) of the Worcester Polytechnic Institute team
(Bourgeois et al 2012), the relay of the findings reported here accrues.

Therefore, the present study generates a demand for further information which will only be met by extensive research and trials on the adsorption of toxic substances from contaminated water. Obtaining a financial incentive is an essential requirement for our future trials on the effectiveness of biotite in adsorbing glyphosateroundup herbicides since their analyses require complex and costly tests that can only be made using a chromatograph mass spectrometer.

In today's world, there is a relentless search for solutions to the problems engendered by progress. Biotite is a natural, low-cost, and widely available mineral in the planet. Its high adsorption properties hail a breakthrough in pesticide extraction and in the feasibility of supplying drinking water without toxic chemicals that are extremely harmful not only to human beings but to the whole ecosystem.

The study answered questions about the ability of biotite in removing complex compounds such as the pesticides analyzed. However, it raised new questions about the kind of adsorption that predominates in the reactions between biotite and pesticides. Thus, further studies in the field of geochemistry will be required to have a thorough comprehension of the chemisorption and physisorption properties of this mineral containing potassium, iron, magnesium, aluminum, silicate, and hydroxide and its reactions with complex pesticides rich in chlorine, fluorine, hydrogen, nitrogen, carbon, etc. Questions related to whether van der Waals forces or covalent and/or electrostatic interaction of ions predominate must still be answered; thermodynamic studies will also be required to measure the behavior and effects of temperature variation caused by the chemisorption reactions.

The present study calls for extensive complementary research, especially in the chemistry field, on the adsorption properties of black mica, such as the complex reactions involved, saturation levels, adsorption rate per gram of material, among others, also searching the adsorption of other pesticides and contaminants.

We hope that future studies will contribute to a better understanding of this mineral and its potential to improve water quality and, therefore, our quality of life, seeking protection for living organisms against these toxic compounds. 
Acknowledgments The first and second author thanks CNPq (National Counsel of Technological and Scientific DevelopmentBrazil) for the scholarship granted.

Conflict of Interest The authors declare that they have no competing interests.

\section{References}

Aguiar, T. R. Jr., Bortolozo, F. R., Hansel, F. A., Rasera, K., Ferreira, M. T. (2015). Riparian buffer zones as pesticide filters of no-till crops. Environmental Science and Pollution Research, 22, 1-9.

Aguiar, T. R. Jr., Rasera, K., Parron, L. M., Brito, A. G., Ferreira, M. T. (2014). Nutrient removal effectiveness by riparian buffer zones in rural temperate watersheds: the impact of no-till crops practices. Agricultural Water Management, 149, 74-80.

Andreoli, C.V. (1993). Influência da Agricultura na Qualidade da Água. Curitiba. OPS.15 p.

Anthony J. W., Bideaux R. A., Bladh K. W., and Nichols M. C. (2003). Eds., Handbook of mineralogy, Mineralogical Society of America, Chantilly, VA 20151-1110, USA.

Appelgren, B. G. (1994). Agricultural and environmental legislation-Lithuania, technical report. FAO-LEG: TCP/LIT/2352, technical cooperation programme. Rome: FAO.

Bourgeois, A., Klinkhamer, E., \& Price, J. (2012). Pesticide removal from water. A major qualifying project completed in partial fulfillment of the bachelor of science degree Worcester. Worcester: Polytechnic Institute. 93 pp.

Chakraborty, S., Wolthers, M., Chatterjee, D., \& Charlet, L. (2007). Adsorption of arsenite and arsenate onto muscovite and biotite mica. Journal of Colloid and Interface Science, 309(2), 392-401. doi:10.1016/j.jcis.2006.10.014.

Dabrowski, A. (2001). Adsorption from theory to practice. Advances in Colloid and Interface Science, 93, 135-224.

Damalas, C. A., \& Eleftherohorinos, I. G. (2011). Pesticide exposure, safety issues, and risk assessment indicators. International Journal of Environmental Research and Public Health, 8, 1402-1419. doi:10.3390/ijerph8051402.

Dana, E.S. (1981). Dana's system of mineralogy, (6th edition), 627- 632 .

Elsabawy, K. M., Sekkina, M. A., \& Tawfik, A. T. (2012). Green synthesis of nano-V-biotite for removal of toxic heavy metals, Th(IV) and U(VI) from aqueous solutions. ARPN Journal of Science and Technology, 2(8), 686-696. ISSN 2225-7217.
Gold, L. S., Slone, T. H., Ames, B. N., \& Manley, N. B. (2001). Immunotoxicity of pesticides. In R. Krieger (Ed.), Handbook of pesticide toxicology (pp. 769-778). San Diego: Academic. doi:10.1016/B978-0-12-374367-1.00128-2.

Hashmi, I., Dilshad, K, A. (2011). Adverse health effects of pesticides exposure in agricultural and industrial workers of developing country. pp 155-178 In Margarita Stoytcheva (Eds) Pesticides-The impacts of pesticides exposure. ISBN: 978-953-307-531-0. InTech.

Howie R.A., Zussman J. (1963). Rock-forming minerals, v. 3, sheet silicates, 55- 84 .

Lampman, M. (1995). Susceptibility of groundwater to pesticide and nitrate contamination in predisposed areas of southwestern Ontario. Water Quality Research Journal of Canada, 30, 443-468.

Libânio, M., Rissato, S.P., Melo, N.A.S. (2005). Avaliação das perspectivas de remoção de pesticidas organoclorados estações de tratamento de água. $23^{\circ}$ Congresso Brasileiro de Engenharia Sanitária e Ambiental. ABES- Associação Brasileira de Engenharia Sanitária e Ambiental.

Mannini, M. (2009). Molecular magnetic materials on solid surfaces. Firenze University Press. Premio Tesi Dottorato. ISBN-978-888453-901-4.

Moreira, L.F. \& Cruz, J.C.S. (1996). Uso correto e seguro de fitossanitários. Viçosa, MG: EMATER; DETEC; Departamento Técnico. Não paginado.

Regitano, J.B., Bonfleur E.J. (2011). Pesticides residues in the environment: Processes. II Simpósio Internacional sobre Gerenciamento de Resíduos Agropecuários e Agroindustriais-II SIGERA. 15 a 17 Março de 2011-Foz do Iguaçu, PR. Volume I-Palestras.

Rigitano, R. L. O., \& Barbosa, T. M. L. (1994). Influência da classe e profundidade do solo na degradação do inseticidanematicida aldicarb. Pesquisa Agropecuária Brasileira, 29, 955-960.

Rissato, S. P., Libânio, M., Giafferis, G. P., \& Gerenutti, M. (2004). Determinação de pesticidas organoclorados em água de manancial, água potável e solo na região de Bauru (SP). Quim Nova, 27(5), 793-743.

Sanches, S.M., Da Silva, C.H.T., Campos, S.X., Vieira, E.M. (2003). Pesticidas e seus respectivos riscos assicoados à contaminação da água. Pesticidas: R. Ecoxicol. e Meio Ambiente, Curitiba, v.13, p.53-58.

SANCO (2006). Quality control procedures for pesticide residue analysis.[S.1.]: Directorate general. Health and consumer protection: European Commission. SANCO/ $10232 / 2006$.

U.S. EPA. (1992). Another look: national survey of pesticides in drinking water wells, phase II report. EPA 579/09/-91-020. Washington, DC: U.S. EPA. 1992a. 